\title{
Aplikasi Microsoft Excel Dalam Penyelesaian Masalah Rata-rata Data Berkelompok
}

\section{Microsoft Excel Application in Solving The Average of Group Data Problems}

\author{
${ }^{1 *}$ Devy Andriyani, ${ }^{1}$ Erwin Harahap, ${ }^{1} \mathrm{FH}$ Badruzzaman, ${ }^{1} \mathrm{M}$. Yusuf Fajar, ${ }^{2}$ Deni Darmawan \\ ${ }^{1}$ Program Studi Matematika, Universitas Islam Bandung \\ ${ }^{2}$ Program Studi Teknologi Pendidikan, Universitas Pendidikan Indonesia \\ *devyandryn_10060217019@unisba.ac.id
}

\begin{abstract}
Abstrak. Era digital menuntut segala bentuk aktivitas dikerjakan dengan cepat, efektif, dan efisien, dengan pemanfaatan teknologi yang mutakhir. Pada era reformasi teknologi 4.0 saat ini, berbagai informasi dapat diperoleh dalam waktu yang singkat melalui perangkat pintar dengan aplikasi tertentu, salah satunya adalah aplikasi untuk menghitung nilai rata-rata. Penyelesaian masalah nilai rata-rata pada data berkelompok memerlukan suatu usaha perhitungan yang teliti dan kompleks. Pada artikel ini penulis menguraikan sebuah aplikasi untuk penyelesaian masalah perhitungan nilai rata-rata pada data berkelompok secara efektif, cepat, dan akurat dengan menggunakan software Microsoft Excel.
\end{abstract}

Kata kunci: microsoft excel, rata-rata data berkelompok, aplikasi matematika

\begin{abstract}
Digital era can demand all of activity to working with quick, effective, and efficient with utilization a up to date's technology. In the era of Reformation Technology 4.0, various information was obtained in a short time via smart device with particular application, one of them is application to calculate average. Finishing a average's problem in group data can make a careful and complex calculation effort. In this article, the author outlines a application for completed a problem of calculate average for group data with effective, quick, and accurate with using a Microsoft Excel
\end{abstract}

Keywords : Microsoft Excel, average group data, application in mathematics

\section{Pendahuluan}

Era saat ini adalah era digital dimana segala bentuk aktivitas dapat dikerjakan dengan mudah karena adanya bantuan teknologi. Saat ini, seluruh pengguna dapat memperoleh berbagai informasi dalam waktu yang sangat cepat melalui suatu perangkat pintar baik berupa smartphone, tablet, atau juga pc/ laptop. Melalui perangkat tersebut, pengguna dapat memanfaatkan berbagai macam aplikasi untuk mendukung berbagai aktifitas, diantaranya adalah sebagai alat bantu pembelajaran, evaluasi/test, dan untuk alat bantu menyederhanakan perhitungan yang rumit dan kompleks [1-6, 11-13]. Pada artikel ini, penulis akan menguraikan mengenai aplikasi untuk penyelesaian rata-rata data berkelompok (RTDB). Aplikasi ini merupakan salah satu alternatif solusi untuk pemecahan permasalahan Matematika khususnya untuk perhitungan rata-rata data berkelompok.

Tujuan dari penulisan artikel ini adalah untuk menyusun aplikasi RTDB dengan menggunakan software Microsoft Excel. Aplikasi ini dapat diakses melalui media smartphone, tablet, atau juga PC/Laptop. Manfaat dari kajian ini adalah diharapkan aplikasi RTDB dapat menyederhanakan perhitungan rata-rata dari suatu data berkelompok sehingga proses pengerjaan menjadi relatif lebih cepat dan akurat. 


\section{Landasan Teoritis}

\subsection{Microsoft Excel}

Microsoft Excel (Ms. Excel) merupakan salah satu program dari keluarga Microsoft Office yang berbasis pada sistem operasi Windows [7-11]. Ms. Excel berfungsi untuk memproses data berupa angka atau bilangan dengan menggunakan spreadsheet yang terdiri dari baris dan kolom. Ms. Excel telah menjadi aplikasi pemroses data dan angka yang paling umum digunakan, dan dapat digunakan pada berbagai media seperti PC, tablet, atau smartphone. Microsoft Excel tidak hanya tersedia dalam platform Windows, tetapi juga tersedia pada sistem operasi MacOS, Android dan Apple IOS. Ms. Excel menggunakan spreadsheet untuk menjalankan berbagai formula. Spreadsheet adalah kumpulan dari sel yang terdiri atas baris dan kolom sebagai tempat dimana angka dan data diolah.

\subsection{Rata-rata Data Berkelompok}

Data berkelompok adalah data yang sudah tersusun atau dikelompokkan ke dalam kelas-kelas interval [9]. Setiap kelas pada umumnya memiliki panjang interval yang sama. Untuk data berkelompok, rata-rata data dihitung dengan menggunakan tiga metode, yaitu metode titik tengah, simpangan rata-rata data sementara, dan coding.

\section{Metode}

\subsection{Metode Titik Tengah}

Dalam perhitungan rata-rata data berkelompok diambil titik tengahnya, yaitu setengah dari jumlah ujung bawah kelas dan ujung atas kelas untuk mewakili setiap kelas interval. Apabila telah dibentuk distribusi biasa, maka rata-rata hitung dapat dihitung dengan rumus:

$$
\bar{x}=\frac{\sum_{i=1}^{k} f_{i} x_{i}}{\sum_{i=1}^{k} f_{i}}
$$

dimana,

$f_{i}$ : frekuensi pada interval kelas ke- $i$

$x_{i}$ : titik tengah interval kelas $\mathrm{i}$

\subsection{Metode Simpangan Rata-rata Data Sementara}

Dalam metode ini dipilih salah satu nilai dari keseluruhan data sebagai rata-rata dan simpangan rata-rata yang dirumuskan sebagai berikut [9]:

$$
\bar{x}=\bar{x}_{s}+\frac{\sum_{i=1}^{k} f_{i} d_{i}}{\sum_{i=1}^{k} f_{i}}
$$

Dimana: $d_{i}=x_{i}-x_{s}$, dan $\bar{x}_{s}=$ rata-rata sementara

Nilai rata-rata data sementara diperoleh dari titik tengah pada frekuensi terbesar yang ada pada data. Nilai simpangan d diperoleh dari setiap titik tengah dikurangi dengan rata-rata data sementara.

\subsection{Metode Coding}

Metode coding sering digunakan apabila ditemukan nilai-nilai dalam data berupa bilanganbilangan besar. Pada dasarnya metode coding merupakan penjabaran dari metode simpangan rata-rata [4]. 


$$
\bar{x}=\bar{x}_{s}+\frac{\sum_{i=1}^{k} f_{i} c_{i}}{\sum_{i=1}^{k} f_{i}} p
$$

Dimana: $x=$ rata-rata hitung data berkelompok, $\bar{x}_{s}=$ rata-rata sementara, $f_{i}=$ frekuensi data kelas ke- $i$, $x_{i}=$ Nilai tengah kelas ke- $i, c_{i}=$ kode kelas ke- $i, p=$ panjang interval.

\section{Hasil dan Pembahasan}

\subsection{Aplikasi RTDB pada Microsoft Excel}

Aplikasi RTDB merupakan sebuah aplikasi yang bertujuan untuk memudahkan pengguna dalam menghitung rata-rata data berkelompok, agar dapat diselesaikan dengan cepat, tepat, dan akurat. Aplikasi ini dapat diakses melalui PC, smartphone, dan juga tablet. Cara menggunakan aplikasi ini adalah dengan memasukkan nilai yang akan dihitung dengan nilai frekuensi tertentu. Selanjutnya dengan mengeksekusi tombol atau perintah tertentu, maka dihasilkan nilai rata-rata berkelompok.

Berikut ini adalah formula yang dipakai dalam aplikasi RTDB:

a. Penentuan nilai tengah interval

Penentuan nilai tengah interval ditunjukkan pada gambar 1. Misalkan $\mathrm{x}$ adalah nilai tengah antara interval atas dan interval bawah, rumus yang dipakai di aplikasi ini adalah (B3+D3)/2. Dengan menggunakan rumus tersebut, maka nilai x dapat diketahui.

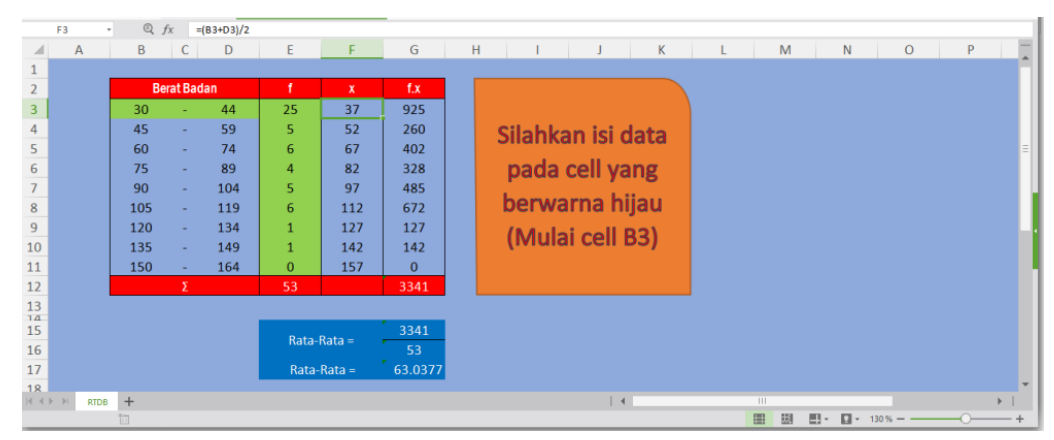

Gambar 1. Menentukan Nilai Tengah Interval

b. Penentuan nilai f.x

Penentuan nilai f.x ditunjukkan pada gambar 2. Misalkan f.x adalah nilai frekuensi dikalikan dengan nilai tengah antara interval atas dan interval bawah. Rumus yang digunakan adalah E3*F3. Sel E3 memuat nilai $f$, sedangkan F3 adalah sel yang memuat nilai $x$.

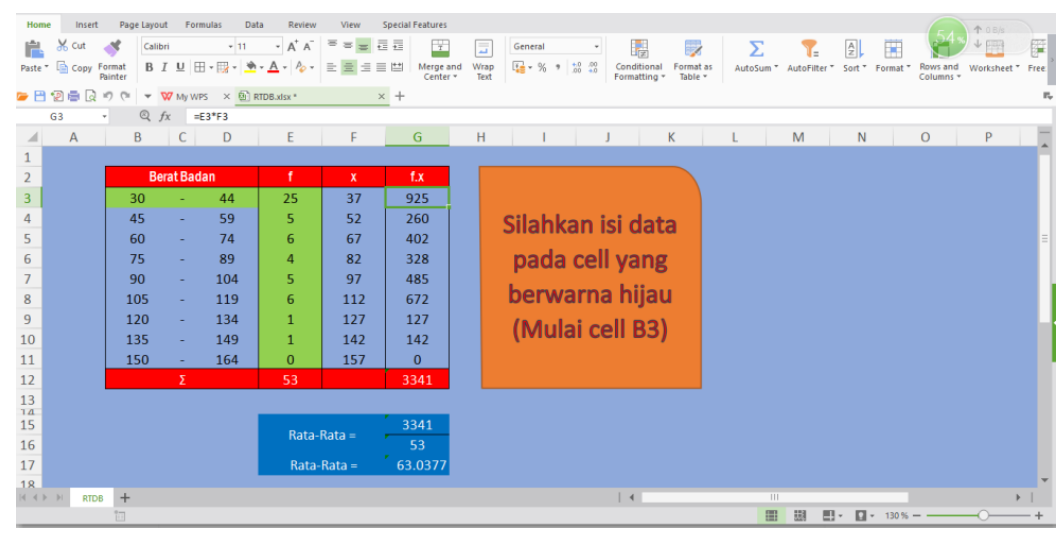

Gambar 2 Menentukan Nilai f.x 
c. Menghitung jumlah dari sebuah data frekuensi

Untuk menghitung jumlah dari sebuah data frekuensi digunakan rumus SUM(E3:E11) sebagaimana ditunjukkan pada Gambar 3. Sel E3 adalah frekuensi pada interval pertama, dan sel E11 adalah frekuensi pada interval terakhir.

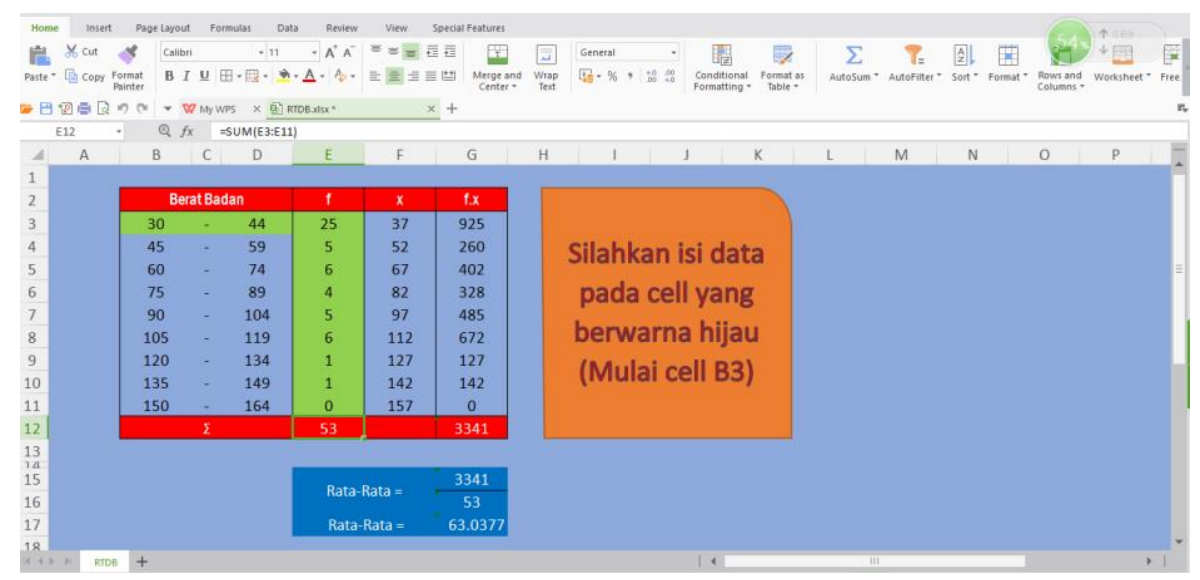

Gambar 3 Menghitung Jumlah Frekuensi

d. Menghitung jumlah dari sebuah

Untuk menghitung jumlah dari sebuah data digunakan rumus SUM(G3:G11) sebagaimana ditunjukkan pada Gambar 4. Pada sel G3 berisi nilai hasil kali frekuensi dengan nilai tengah pada interval pertama, dan G11 adalah nilai hasil kali frekuensi dengan nilai tengah pada interval terakhir.

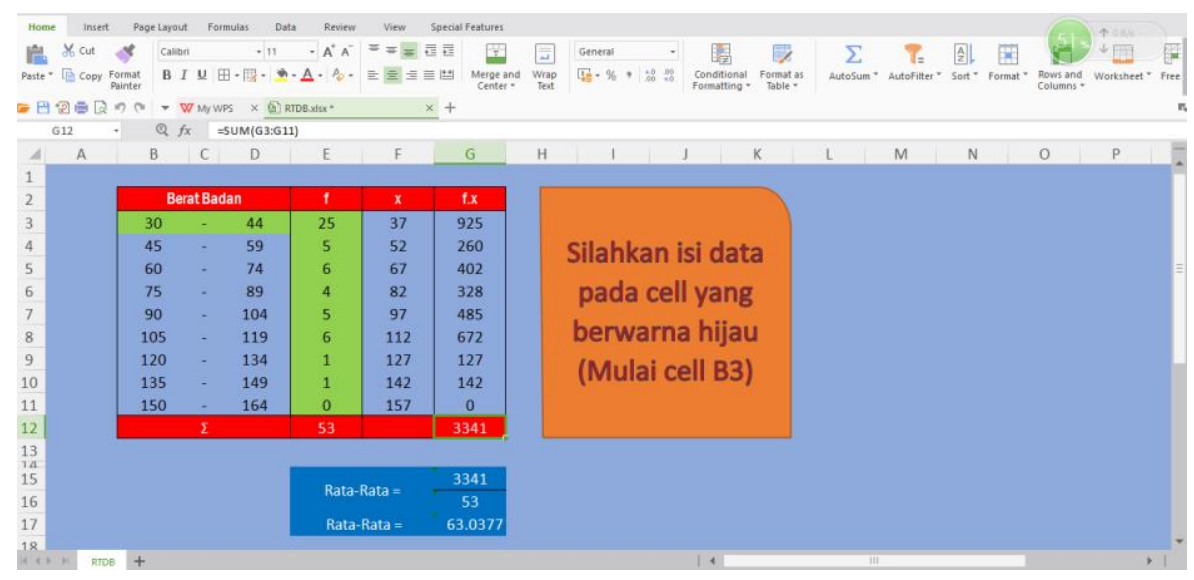

Gambar 4 Menghitung jumlah dari sebuah data

e. Menghitung rata-rata data berkelompok

Untuk menghitung rata-rata data berkelompok, digunakan rumus G12 dibagi dengan E12, sebagaimana ditunjukkan pada Gambar 5. Sel G12 berisi jumlah nilai frekuensi dikalikan dengan nilai tengah interval, sedangkan E12 adalah jumlah nilai frekuensi. Dengan menggunakan rumus tersebut dapat diketahui nilai rata-rata kelompok dari data yang diinputkan 


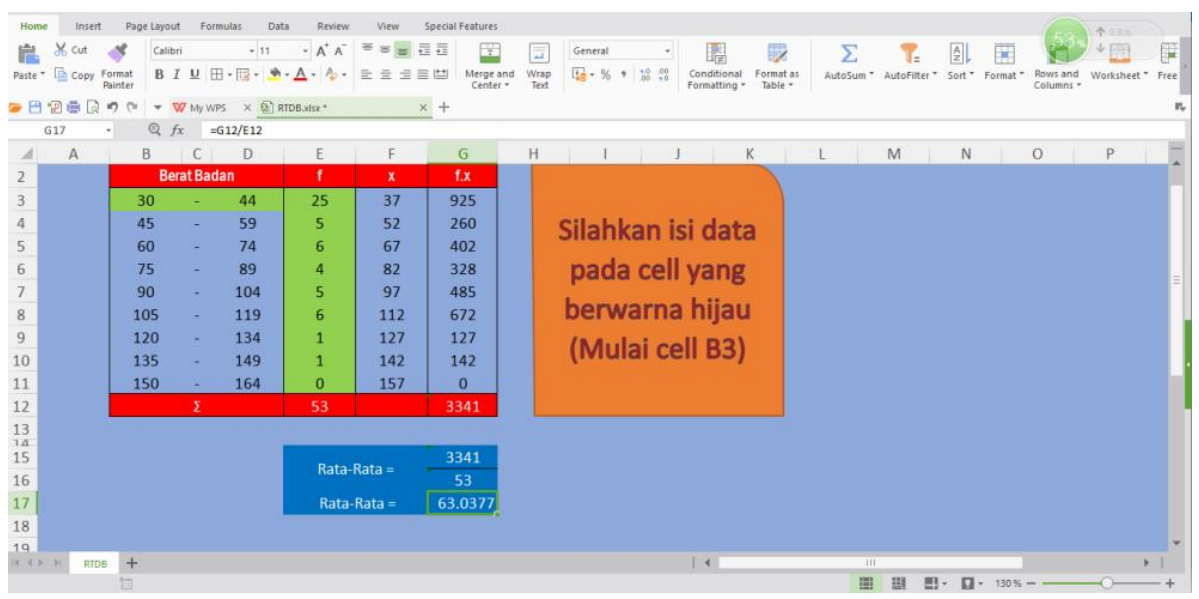

Gambar 5 Menghitung rata-rata data berkelompok

\subsection{Tampilan Aplikasi}

Aplikasi RTDB diakses melalui PC. Caranya adalah dengan mengakses file RTDB melalui aplikasi Ms. Excel pada operating sistem Windows atau MacOS. Tampilan aplikasi RTDB pada PC ditunjukkan pada Gambar 6.

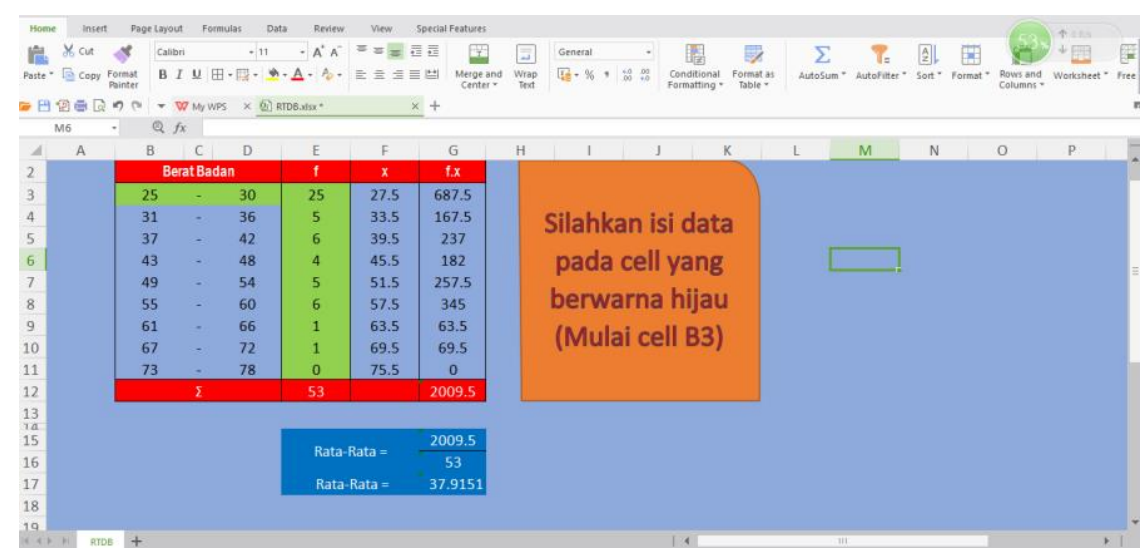

Gambar 6 Tampilan Aplikasi RTDB pada PC

Aplikasi RTDB dapat diakses melalui smartphone. Caranya adalah dengan mengakses file RTDB melalui aplikasi Ms. Excel online pada android atau IOS. Tampilan aplikasi RTDB melalui smartphone ditunjukkan pada Gambar 7

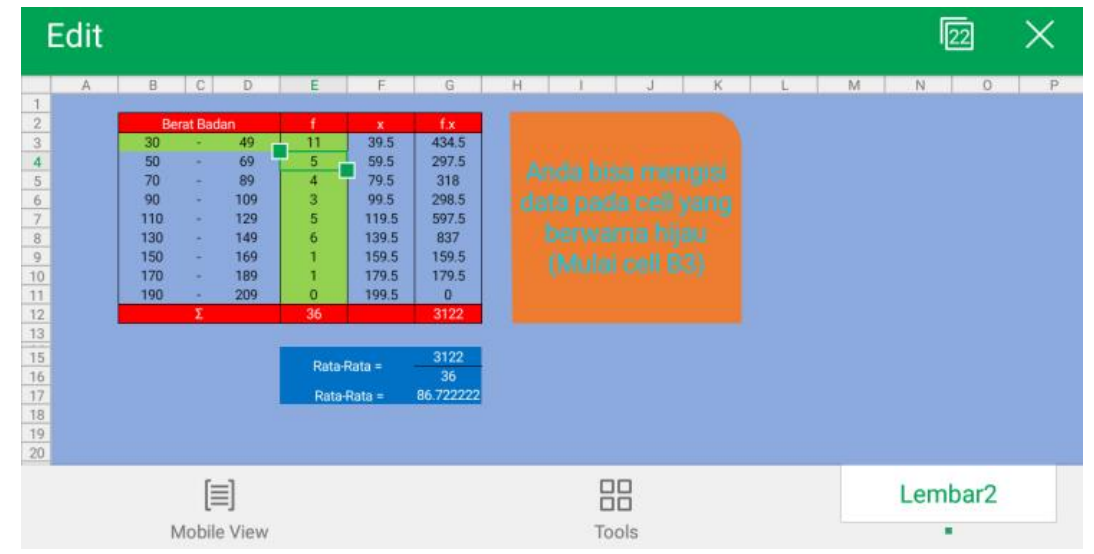

Gambar 7 Tampilan Aplikasi RTDB pada Smartphone 


\subsection{Cara Menggunakan Aplikasi RTDB}

Cara menggunakan aplikasi RTDB adalah sebagai berikut:

a. Masukkan nilai ujung atas dan ujung bawah yang kita butuhkan pada kolom B3 dan D3

b. Masukkan nilai frekuensi dari interval pertama sampai interval terakhir pada kolom E3 sampai E11

c. Setelah kita memasukkan nilai ujung atas dan ujung bawah serta nilai frekuensi, kita bisa mengetahui nilai rata-rata dari data yang anda miliki.

\section{Kesimpulan dan Saran}

Dari penelitian yang telah dilakukan maka dapat disimpulkan bahwa Microsoft Excel dapat digunakan sebagai aplikasi Matematika untuk memecahkan permasalahan rata-rata data berkelompok. Aplikasi ini dapat digunakan oleh berbagai kalangan untuk menyelesaikan permasalahan rata-rata data berkelompok secara cepat, tepat, dan akurat. Semoga pengembang aplikasi selanjutnya bisa memecahkan permasalahan rata-rata data berkelompok ini dengan menggunakan metode lain, diantaranya adalah dengan menggunakan simpangan rata-rata atau dengan cara koding.

\section{Referensi}

[1] D Darmawan, E Harahap, Communication Strategy For Enhancing Quality of Graduates Nonformal Education Through Computer Based Test (CBT) in West Java Indonesia, International Journal of Applied Engineering Research Vol 11, No 15, 2016, pp. 8641-8645.

[2] IL Nur'aini, E Harahap, FH Badruzzaman, D Darmawan, Pembelajaran Matematika Geometri Secara Realistis Dengan GeoGebra, Jurnal Matematika, Vol 16, No 2, 2017.

[3] MY Fajar, E Harahap, I Sukarsih, O Rohaeni, D Suhaedi, Implementation of Lesson Study on Integral Calculus Course, Proceedings International Conference on Lesson Study (ICLS 2017), Lombok NTB, Indonesia. 14-16 September 2017.

[4] E Harahap, I Sukarsih, G Gunawan, MY Fajar, D Darmawan, H Nishi, A Model-Based Simulator for Content Delivery Network using SimEvents MATLAB-Simulink, INSIST Journal, Vol 1 No 1, 2016. pp. 30-33.

[5] R Tennekoon, J Wijekoon, E Harahap, H Nishi, E Saito, S Katsura, Per hop data encryption protocol for t ransmission of motion control data over public networks, Proceedings Advanced Motion Control (AMC), IEEE 13th International Workshop, 2014. Pp. 128-133.

[6] T Asmara, M Rahmawati, M Aprilla, E Harahap, D Darmawan, Strategi Pembelajaran Pemrograman Linier Menggunakan Metode Grafik Dan Simpleks, Jurnal Teknologi Pembelajaran Sekolah Pascasarjana IPI Garut, Vol 3, No 1, 2018. pp. 506-514.

[7] Hadi, M.S., Mengenal Microsoft Excel Untuk Pemula, Jakarta, Tiara Aksa. 2008.

[8] Sumardi, Y., Penggunaan Microsoft Excel Dalam Analisis Data Eksperimen Pada Pembelajaran Fisika, Jurnal Cakrawala Pendidikan, No.2. 2002.

[9] Tung, K.T., Kumpulan Rumus Lengkap Matematika SMA/MA IPA/IPS. Jakarta, Kompas Gramedia. 2006.

[10] E Harahap, Modul Praktikum Microsoft Excel, Program Studi Matematika, Universitas Islam Bandung, 2017.

[11] SF Fitria, E Harahap, F Badruzzaman, MY Fajar, D Darmawan., Aplikasi Rata-rata Data Tunggal. Prosiding Seminar Nasional Pendidikan Matematika Ahmad Dahlan 6, 2019.

[12] S Zein, L Yasyifa, R Ghozi, E Harahap, FH Badruzzaman, D Darmawan., Pengolahan dan Analisis Data Kuantitatif Menggunakan Aplikasi SPSS. Jurnal Teknologi Pembelajaran, 4 (1), 2019.

[13] G Utami, F Julian, A Fadilah, E Harahap, F Badruzzaman, D Darmawan., Pembelajaran Mengenai Penyelesaian Pengolahan Data Statistika Secara Efektif Menggunakan Speq Mathematics. Jurnal Teknologi Pembelajaran 4 (1), 2019. 